\title{
Quality Teaching Practices in the Jordanian Inclusive Primary Classrooms
}

\author{
Mohammad Sakarneh ${ }^{1}$ \\ ${ }^{1}$ Department of Special Education, Princess Rahma University College, Al-Balqa' Applied University, Amman, \\ Jordan \\ Correspondence: Mohammad Sakarneh, Department of Special Education, Princess Rahma University College, \\ Al-Balqa' Applied University, P.O. Box 371, Marj Al-Hamam, 11732 Amman, Jordan. E-mail: \\ msakarneh@gmail.com
}

Received: July 4, 2013 Accepted: August 12, 2014 Online Published: September 29, 2014

doi:10.5539/ass.v10n19p113 URL: http://dx.doi.org/10.5539/ass.v10n19p113

\begin{abstract}
The aim of this study was to compare and contrast the Jordanian Ministry of Education ideal quality teaching practices with the actual quality teaching practices in inclusive primary classrooms. The study was restricted to seven primary school teachers in Jordan. A qualitative approach of data gathering and analysis was used. For data gathering: observations and documents analyses were used. One key finding was that there were some congruities between the ideal and the actual quality teaching practices. The results of this study were discussed. Future directions for policy and practices were presented.
\end{abstract}

Keywords: inclusion, primary classrooms, quality teaching practices

\section{Introduction}

The concept of quality teaching has been a core issue debated in educational circles both in Jordan and elsewhere. The education system in Jordan, as in many other countries, has undergone significant change in all aspects, including curriculum and textbooks, length of schooling, and teaching practices to cope with the structural problems of a country facing serious problems filling professions and creating employment (Alshurfat, 2003). The Ministry of Education (MOE), however, consistently considered teachers' roles in rhetorical rather than practical terms. As mentioned before, the impetus for educational reform in both Jordan and the rest of the world came from the ideas and concepts of a constructive orientation (Alshurfat, 2003; Chorrojprasert, 2005; Fullan, 1997; Hargreaves, 2003; McLaughlin \& Talbert, 1993). However, there are many fundamental challenges and issues that are still impeding and restraining reform. A related issue is that graduates of Jordanian schools have been described as lacking crucial knowledge and being weak in their critical thinking skills. So, despite the Government's move to reform the education system in Jordan, studies conducted to evaluate the results of the reforms have shown that students still demonstrate low skills in relation to critical thinking. Furthermore, since the reforms began, students' basic skills and concepts in mathematics and science and performance in Arabic have not improved (Anani \& Al-Qaisee, 1994). Another study showed that teachers still dominated most lesson time and did not give their students an opportunity to express and/or direct themselves nor direct their own learning activities (Alnahar \& Kishik, 1994).

If any education reform to be successful, the dimensions of quality teaching should be included, taught, trained and implemented to meet the aims of that reform. To prevent this reform from failing, comparing and contrasting should be done to explore the gap -if there is-between the ideal quality teaching practices and actual practices of quality teaching to make sure that the mission and vision of the MOE has been understood and implemented. This study was conducted to fill the growing gap between the policy and the practices of the education reform movement in Jordan.

\section{Objectives}

This study aimed to compare and contrast the ideal quality teaching identified by the MOE's official documents and the actual quality teaching practices observed in the inclusive primary classrooms judged by the NSW Quality Teaching Model. To achieve appropriate insight information about quality teaching practices, it is 
essential to know how quality teachers in Jordan are practicing their day-to-day teaching and to explore the extent to which they already meet the MOE's criteria of quality teaching.

\section{Research Questions}

In order to achieve this overarching aim and the objectives outlined above, the study was guided by the following research questions:

1. How is quality teaching described officially in Jordan?

2. What are the current quality teaching practices in Jordanian inclusive primary schools?

3. What are the variations between the ideal and actual of quality teaching?

\section{Literature Review}

\subsection{Teaching Presentation and Teacher's Task Orientation}

The current debate within education systems is over the call for teaching to focus more on student reception than teacher transmission, which is teaching that encourages students to use their minds rather than treating them as passive receivers. This is then about creating a method for teaching that allows students to use their intellectual abilities to reach a high standard. To achieve acceptance for this view/concept, educators need to show the 'new approaches to pedagogy are grounded in high intellectual standards' (Newmann et al., 1996, p. 282) and adherence to those standards enhances students' achievement. A quality teacher uses the students' prior knowledge, giving the students the opportunity to be thinkers and for them to gain a deep understanding of the information they have been taught. Teaching approaches have been developed or explored progressively by researchers through history. Newmann and Associates (1996) define authentic pedagogy or authentic academic achievement through three criteria: 'construction of knowledge', 'disciplined inquiry' and 'value beyond school' (p. 33). Newmann, Marks and Garmoron (1996) studied 24 schools intensively, observing mathematics and social studies teachers. They found that across elementary, middle and high schools there was a strong relationship between authentic pedagogy and authentic academic performance.

Including students with disabilities in the mainstream has made it essential to look at the context of the teaching practices. In such context, students with disabilities are able to find an accepting and welcoming environment; inclusive education based on professional knowledge is an important characteristic. Ainscow (1991) regards the context of quality teaching as having teachers challenge the students' abilities by setting good quality tasks, providing students with opportunities to choose their tasks, varying learning strategies, and providing facilities that contribute to student learning (Ainscow, 1991). The trend of inclusion raises significant considerations about the characteristics of teachers teaching in inclusive classrooms. Research in this area suggests the effective teacher's characteristics in the inclusive classroom as: efficient use of time, good relationships with students, providing positive feedback, having a high student success rate, and, in general, providing support for the students with and without disabilities (Larrivee, 1985). Larrivee (1985) reported that students with special needs demonstrated a greater level of achievement in the mainstream classrooms when the teacher: used the time efficiently, had a good relationship with the students, gave the students positive feedback, established a high rate of success for learning tasks, and responded to all students positively. King, Schroeder and Chawszczewski (2001) found that students with disabilities taught by teachers using a high level of authentic pedagogy performed at the same levels as students without disabilities whom receiving a lower level of authentic pedagogy.

To further address issues around students with low prior achievement and displaying work with low intellectual quality, Newmann et al. (2001) re-examined students' work from previous studies, especially from students who had low prior achievement. They compared classrooms displaying high intellectual quality with those displaying low intellectual quality. They found that both high and low achievers benefited significantly from high intellectual quality teaching. This means that authentic intellectual tasks are useful and productive not only for special groups of students, but also for all student groups and abilities in the classroom. It is clear that the interaction process between teachers and students needs basic communication skills, relying fundamentally on all uses of language: writing, reading, speaking and listening 'to enable students to 'name', deconstruct and critique forms of spoken language' (University of Queensland, 2001, p. 7). Such a method gives students the ability to vocalise and investigate dilemmas both within and outside the classroom.

\subsection{Students' Self-Regulation, Direction, Knowledge and Instructional Variety}

Some scholars believe that students have both the ability and willingness to control their behaviour and that the teacher's role is to have students gain satisfaction from regulating their behaviour when performing their 
learning tasks (Glasser, 1986; Meichenbaum \& Biemiller, 1998). Therefore, the teacher's role is to make the tasks interesting, enjoyable and engaging so they meet students' internal demands. The teacher-cantered approach of teaching remained a common way of teaching, as mentioned by most teaching studies (Goodlad, 1984). Growing opposition to this meant that a new perspective came to dominate teaching studies: that the students as learners should have the responsibility to determine their own learning (Biggs, 1991). One of the aims of the educational process is to connect the students' background knowledge with new knowledge or information (Bruner, 1960). From a cognitive point of view, quality teaching and learning occurs when the teacher uses and highlights students' background knowledge as a basis for teaching new knowledge. This is called 'scaffolding' (Rosenshine \& Meister, 1992, p. 26). In any teaching-learning process the knowledge across subject areas should be integrated to make learning meaningful for students. A quality teacher makes sure that whatever they teach is integrated into a bigger picture and helps students to connect what they learn with other subject areas or aspects of their lives (Beane, 1993, 1995).

Connectedness runs in concert with inclusiveness, focusing on how the students' knowledge acquired in the classroom is connected to the world beyond the classroom and with the utility of this knowledge for the students in their present and future pursuits. Such teaching strategies have been emphasised in Dewey's and Bruner's work (Bruner, 1960; Dewey, 1916). Smith, Lee and Newmann (2001) also found that interactive teaching methods that include connectedness, along with other intellectual factors, have a significant correlation with learning in mathematics and reading. Also Narrative can play the central role in teaching. For example, indigenous children are thought to learn better through storytelling, especially when the narratives have connections to their communities and their moral and oral traditions (Christie, 1985). Therefore, to make teaching more interesting and enjoyable, quality teachers need to teach knowledge and skills simply and effectively, and approach this as a contextualised form of storytelling that connects closely with and is familiar to students' daily lives and experiences.

\subsection{Evaluation}

There is no doubt about the important role of assessment or evaluation in the teaching-learning process. But there is debate and the controversy is about what sort of assessment. The considerable debate about assessment developed from the work of Nemmann and others; they called for 'authentic assessment' (Killen, 2005; King et al., 2001, p. 1; Newmann et al., 2001). Authentic assessment requires deep knowledge rather than using superficial assessment, such as 'true-false, multiple choice, or short answers' (King et al., 2001, p. 3). Newmann and Associates. (1996), in their research on mathematics and social studies teaching, called for assessment tasks from teachers to determine students' understanding and mastering of the subjects being taught. They asked for the assessment tasks to be written work and 'teachers provided tasks that asked students to write opinion essays, explain solutions to mathematics problems, synthesize research data, draw maps and mathematical diagrams, and complete short-answer tests' (Newmann \& Associates, 1996, p. 28).

\section{Methodology}

\subsection{Participants}

Sample size in qualitative research is relatively small. Therefore, because of the nature of the study, specific participants with known characteristics needed to be selected (May, 2001). The participants included seven quality teachers in inclusive primary schools. The subjects observed were mathematics and Arabic language. These subjects were selected specifically because literacy and numeracy are the main subjects at this stage and also in the foundation stages. Both subjects are good examples for teachers to demonstrate their teaching abilities by applying elements of quality teaching. Each classroom included one or two students with learning disabilities. The researcher used four criteria to identify the quality teachers which were: Supervisors' Recommendations, Principals' Confirmations, Colleagues' Confirmations and Parents' Confirmations.

\subsection{Documents}

To understand the description of the ideal quality teaching concept according to the Jordanian MOE's perspective, the researcher had to refer to and analyze official documents to answer one of the research questions. Official and published documents from the Jordanian MOE were collected and examined.

\subsection{Observation}

Video-recording was use as the researcher was able to capture actions and reactions. While the camera was filming, the researcher observed the teaching and learning process and completed a coding sheet specified for this purpose. The coding sheet was the coding sheet of the New South Wales Quality Teaching model (NSWQT) of quality teaching. This sheet consisted of three dimensions and eighteen elements. Fourteen lessons were 
observed and recorded on seven videotapes, two lessons for each teacher. The subjects were mathematics and the Arabic language. Each lesson lasted 40 minutes. To ensure that the given scores for each teacher were valid and credible, a sample of videotaped lessons was given to an independent rater. This person was fluent in both English and Arabic, had knowledge of the NSWQT Model and had experience in inclusive primary school teaching. For each item and the related question, a rating of 1-5 was given to each lesson; 5 being most evident, 1 being not evident. Table 1 shows these questions and items. The selection of the NSWQT model as an observation instrument was not random. The NSWQT model and the Jordanian MOE's framework draw on the relatively new constructivist approach to teaching and learning for their conceptions of best practice (NSW Department of Education and Training, 2003a, 2003b, 2003c). Therefore, the model shares considerable overlap with the vision of the Jordanian MOE, which, in parallel with ministries in Australia -where was the model developed- is to reform education by constructing a sustainable educational system capable of meeting the next millennium's demands and needs in terms of producing skilled and knowledgeable generations. Furthermore, from reviewing the literature it can be claimed that the model is comprehensive, covering most elements of quality teaching built from a constructivist perspective (NSW Department of Education and Training, 2003, 2003a, 2003b, 2003c). This is the common and desired approach to teaching and learning in the current global education reform movement. The concept of quality teaching is part of the MOE's future vision for education. However, while this vision sees quality education as bringing together multiple aspects of the teaching-learning process, there is no practical guide to quality teaching that is as sophisticated, extensive and comprehensive as the NSWQT Model.

Table 1. NSW-QT classroom observation items and guiding questions by dimension

\begin{tabular}{|c|c|}
\hline \multicolumn{2}{|r|}{ Intellectual Quality } \\
\hline Deep Knowledge & $\begin{array}{l}\text { To what extent is the knowledge being addressed focussed on a small number of key concepts and } \\
\text { the relationships between and among concepts? }\end{array}$ \\
\hline Deep Understanding & $\begin{array}{l}\text { To what extent do students demonstrate a profound and meaningful understanding of central ideas } \\
\text { and the relationships between and among those central ideas? }\end{array}$ \\
\hline Problematic Knowledge & $\begin{array}{l}\text { To what extent are students encouraged to address multiple perspectives and/or solutions? To what } \\
\text { extent are students able to recognise knowledge as constructed and therefore open to question? }\end{array}$ \\
\hline Higher-Order Thinking & $\begin{array}{l}\text { To what extent are students regularly engaged in thinking that requires them to organise, } \\
\text { reorganise, apply, analyse, synthesise and evaluate knowledge? }\end{array}$ \\
\hline Metalanguage & $\begin{array}{l}\text { To what extent do lessons explicitly name and analyse knowledge as a specialist language? To what } \\
\text { extent do lessons provide frequent commentary on language use and the various contexts of } \\
\text { differing language uses? }\end{array}$ \\
\hline Substantive Communication & $\begin{array}{l}\text { To what extent are students regularly engaged in sustained conversations (in oral, written or artistic } \\
\text { forms) about the ideas and concepts they are encountering? }\end{array}$ \\
\hline \multicolumn{2}{|r|}{ Quality Learning Environment } \\
\hline Explicit Quality Criteria & $\begin{array}{l}\text { To what extent are students provided with explicit criteria for the quality of work they are to } \\
\text { produce? To what extent are those criteria a regular reference point for the development and } \\
\text { assessment of student work? }\end{array}$ \\
\hline Engagement & $\begin{array}{l}\text { To what extent are most students, most of the time, seriously engaged in the lesson? To what extent } \\
\text { do students display sustained interest and attention? }\end{array}$ \\
\hline High Expectations & $\begin{array}{l}\text { To what extent are high expectations of all students communicated? To what extent is conceptual } \\
\text { risk taking encouraged and rewarded? }\end{array}$ \\
\hline Social Support & $\begin{array}{l}\text { To what extent is there strong positive support for learning and mutual respect among teachers and } \\
\text { students and others assisting students' learning? To what extent is the classroom free of negative } \\
\text { personal comment or put-downs? }\end{array}$ \\
\hline Students' Self- regulation & $\begin{array}{l}\text { To what extent do students demonstrate autonomy and initiative so that minimal attention to the } \\
\text { disciplining and regulation of student behaviour is required? }\end{array}$ \\
\hline Student Direction & $\begin{array}{l}\text { To what extent do students exercise some direction over the selection of activities related to their } \\
\text { learning and the means and manner by which these activities will be done? }\end{array}$ \\
\hline \multicolumn{2}{|r|}{ Significance } \\
\hline Background Knowledge & $\begin{array}{l}\text { To what extent do lessons regularly and explicitly build from students' background knowledge, in } \\
\text { terms of prior school knowledge, as well as other aspects of their personal lives? }\end{array}$ \\
\hline Cultural Knowledge & To what extent do lessons regularly incorporate the cultural knowledge of diverse social groupings? \\
\hline Knowledge Integration & $\begin{array}{l}\text { To what extent do lessons regularly demonstrate links between and within subjects and key } \\
\text { learning areas? }\end{array}$ \\
\hline Inclusivity & $\begin{array}{l}\text { To what extent do lessons include and publicly value the participation of all students across the } \\
\text { social and cultural backgrounds represented in the classroom? }\end{array}$ \\
\hline Connectedness & $\begin{array}{l}\text { To what extent do lesson activities rely on the application of school knowledge in real-life contexts } \\
\text { or problems? To what extent do lesson activities provide opportunities for students to share their } \\
\text { work with audiences beyond the classroom and school? }\end{array}$ \\
\hline Narrative & To what extent do lessons employ narrative to enrich student understanding? \\
\hline
\end{tabular}

(Ladwig, 2005, p. 77) 


\subsection{Data Analysis}

Because of the unique nature of this study, the researcher analyzed the data in the same manner as they were collected. All observation sheets and the documents were translated from Arabic to English. The researcher had to read and analyze these documents thoroughly analyzed them by developing a category system through the ways of deductive and inductive. For the classroom observations, the researcher first carefully watched the videotapes and transcribed them into text. The texts for each lesson were carefully reread. Each unit of data, which can be a sentence or paragraph, was marked. The purpose was to come up with major codes and sub-codes and to look for specific concepts of quality teaching which were determined in the MOE's framework and the NSWQT Model. In this manner, the researcher worked back and forth between the data and coding construction until the conceptual saturation had been reached.

\section{Results}

\subsection{The Jordanian MOE's Ideal Quality Teaching}

From the MOE's perspective, the following principles of teaching and learning reflect current best educational practices and take into consideration psychological, environmental, developmental, and cognitive factors that can affect the student's ability to learn (Ministry of Education, 2002, 2003a, 2003b, 2004b, 2006a).

\subsubsection{Quality Teaching and Learning Leads to Deep Understanding}

Because learning is not passive, students are supposed to actively participate in learning. Quality learning tasks have a clear purpose and require students to create knowledge from new experiences that make connections to their prior knowledge (Jaradat et al., 1983; Ministry of Education, 2002, 2003b, 2006a).

\subsubsection{Different Learning Needs of Students Can Be Met by Using a Variety of Teaching Methods}

According to the MOE, a variety of teaching methods is required to address different learning approaches and to allow students to benefit from exposure to their preferred and non-preferred learning styles (Ministry of Education, 2003b, 2006a).

\subsection{Student-Centred Activities Enable Students to Achieve and Apply Their Learning to Life}

According to the MOE, a curriculum or classroom that is learner-centred allows consideration to be given to individual students as needed. Teachers do not judge their own success exclusively by whether they have presented all the subject material. They focus on maximizing learning for their students and following the interests and abilities of the students (Ministry of Education, 2003b, 2006a).

\subsubsection{Significance of Teaching and Learning}

Real-life activities are those that relate to the world of the student outside of school. The use of real-life activities motivates students to learn, helps to illustrate new concepts, and helps students' knowledge. Lessons that involve topics of interest help students to make connections to what they already know and to develop new concepts with connections to the world outside of the school (Jaradat et al., 1983; Ministry of Education, 2003a, 2003b, 2006a).

\subsubsection{Teaching and Learning Strategies that Meet Quality Teaching Practices}

The MOE deigned a range of strategies for teachers to choose from to achieve the desired learning, but the teaching and learning strategies need to be those with which the teachers are comfortable. It is important that a teaching strategy is selected with an underlying rationale. For example, for a teacher to say: 'Today, we're going to do group work', they have to know why working in groups is the best way to achieve a particular knowledge. The teaching strategies included are grouped as: direct instruction, problem solving and investigation, group learning, and activity-based learning (Ministry of Education, 2003b, 2006a). In the following section, the researcher illustrates one teaching strategy that is mentioned in the MOE' Framework for Curriculum and Assessment.

\subsubsection{Learning Strategy: Using Critical Thinking}

Critical thinking is the use of analysis, evaluation and reflection. It requires creativity and independence. Critical thinking involves: metacognition, visual organisers and analysis (Ministry of Education, 2003b, 2006a).

\subsubsection{Teaching and Learning Environment}

Jordan's new curriculum provides all students with an opportunity to learn. According to the MOE, student learning is influenced by a number of factors, including the student's learning needs, gender, geographical location, and social background. Quality teachers understand the importance of creating classrooms that are equitable and safe for all students and accommodate a diversity of student needs (Ministry of Education, 2003b, 
2006a). The following sections will describe the desired elements of the quality learning environment from the MOE's perspective.

\subsubsection{Equity and Safety}

Successful classrooms do more than provide students with basic competencies. They promote Arabic and Islamic values, beliefs and traditions, and foster positive social development. It is important that the curriculum in Jordan reflects the wide range of behaviours and attitudes available to all citizens (Jaradat et al., 1983; Ministry of Education, 2002, 2003b, 2004b, 2006a).

\subsubsection{Accommodating Student's Needs}

According to the MOE, qual ity teachers should also take into account those students who have been identified with specific learning disabilities, or who are gifted learners. Quality teachers choose instructional strategies and learning resources that accommodate the needs of all their students, using different strategies to assist them to meet these needs (Jaradat et al., 1983; Ministry of Education, 1996, 2003b, 2006a).

\subsubsection{Assessment and Evaluation of Learner Outcomes}

Assessment is an on-going process aimed at improving both student learning and the instruction provided by teachers. Quality assessment builds skills on self-assessment and reflection both for the student and for the teacher. According to the MOE, a good system of assessment, evaluation and reporting should be based on clearly-stated student outcomes (Jaradat et al., 1983; Ministry of Education, 2002, 2003b, 2006a).

\subsection{The Actual Quality Teaching Practices: Congruity across the Seven Teachers}

From a general examination of the teaching and learning practices, the following points can be concluded. First, the three main dimensions and the 18 elements of the model were congruent with teaching and learning practices in Jordanian inclusive primary schools, with scores mostly 3 and 4. Second, the dimension of quality learning environment and most of its elements were congruent with the teaching and learning practices more than the other two dimensions, with most scores 3 and 4. However, during Jamal's lessons, the dimensions of intellectual quality and quality learning environment and most of their elements were most congruent with the teaching and learning practices, more so than the dimension of significance. Some elements in the dimension of significance scored lower than the other dimensions (scores were between 1 and 2). Third, from the observations, it can be suggested that the applicability or congruence of the three dimensions were clearer in the Arabic language lessons more than the mathematics lessons, as the scores were higher in Arabic language lessons. Fourth, from close examination of the congruity of the elements across the three dimensions, it can be said that the elements of student direction, cultural knowledge, problematic knowledge and narrative were either not evident or low during the 14 lessons. Nevertheless, during the two lessons of Jamal, the elements of problematic knowledge, student direction, cultural knowledge and narrative were not evident during the mathematics lesson and low in the Arabic language lesson. Further, during the observed lessons of Jamal, the element of students' self-direction, knowledge integration and connectedness were scored lower than other elements. During Samar's two lessons, the elements of problematic knowledge, higher-order thinking, metalanguage, background knowledge and knowledge integration were more congruent in the Arabic language lesson, with scores mostly 4, than in the mathematics lesson with scores mostly 2 . The element of student self-regulation was low during the two lessons scoring 2 in both. During Sharefa's two lessons, there was significant unevenness in the scores between the Arabic language lesson and the mathematics lesson on the elements of problematic knowledge, knowledge integration, connectedness and narrative, the scores being 2 and 1, 4 and 1, 4 and 3, and 4 and 1 respectively. During Mahmmoud's two lessons, problematic knowledge, background knowledge, knowledge integration, connectedness and narrative scored significantly higher and were more evident during the Arabic language lesson than the mathematics lesson; scores were: 3 and 1, 4 and 1, 4 and 1, 3 and 1, and 3 and 1 respectively. Finally, the element of cultural knowledge was not a feature of any the 14 lessons. The congruity of the three main dimensions and the 18 elements and of the NSWQT Model will be discussed in more detail.

\section{Discussion}

Despite the major congruities between the Jordanian MOE's ideal quality teaching and actual quality teaching practices there are some incongruities between the ideal and actual.

\subsection{Intellectual Quality}

In actual practices, the element of problematic knowledge was not observed to the degree the frameworks would prefer. This incongruence may be explained by the Jordanian context where the stakeholders consider knowledge from what appears to be an authoritative source to be the 'truth' that cannot be questioned, as in the transmission 
(teacher-centred) approach. This then replicates itself in turn where the teacher sees themselves as the only source of knowledge and this knowledge is presented as fact and, as a fixed body of truth, is not open to questioning. This incongruity tends to slightly undermine the MOE's vision. In some lessons, the elements of problematic knowledge, higher-order thinking and metalanguage were more obvious in the Arabic language lessons than in the mathematics lessons. These findings are consistent with the some of the literature; for instance Gore, Griffiths, \& Ladwig (2001) argued that some elements of these dimensions are difficult to apply to some subject areas.

An explanation for this inconsistency may be that in Jordan, Arabic is the national language and the language of instruction. Therefore, teachers' and students' knowledge of and facility with the Arabic language are more connected to their real life, school life and everyday practices. This allows teaching in this subject to be more contextually connected and enable the students to engage in more complexes, deeper, subtle and/or sophisticated ways with the tasks at hand. On the other hand, no matter that any student's facility with Arabic, teaching concepts in mathematics requires more special preparation than teaching Arabic. However, primary teachers are taught at university to have a broad, relatively superficial knowledge across all subjects, while secondary teachers are taught a subject in depth to teach that specific subject. It may be the case that had this study had been conducted in the context of a secondary classroom, the results for teachers' engagement with and even explication of this dimension and some of its more 'difficult' elements may have been different.

\subsection{Quality Learning Environment}

The element of student-direction was incongruent with the MOE's requirements. Students believe and accept authorities, such as parents and teachers, and students generally comply willingly with their direction. Students in Jordanian schools generally come from extended families and from a generally 'collectivist culture'; this may explain this incongruence (Rudy, Grusec, \& Wolfe, 1999, p. 299). This contrasts with western culture, from which the model derives and in which student self-direction is valued. In western culture, as an 'individualistic culture', children are taught to be autonomous and self-directed and children, ideally, are treated in an 'authoritative' not 'authoritarian' manner (Rudy et al., 1999, p. 299). The crucial point, however, is that the MOE has included this element of student self-direction in its vision for quality education. It is seen as one of the attributes needed for building a knowledge economy. However, the gap between the MOE's requirements and Jordanian culture may ultimately hinder attempts to implement this element and foment teacher and student resistance and resentment. The element of student self-regulation was also low in some of the observed lessons. Some of the observed teachers were teaching in overcrowded classrooms where they needed to keep constant control of student behaviour to avoid disruptions. Student self-regulation had low congruence with the models' intentions: here the teacher regulated the students; the students rarely fully regulated themselves. It can be argued that Jordanian culture promotes teacher-centred control and regulation of the classroom; thus the constant reiteration by the stakeholder-informants that quality teachers are able to control their students. The teacher's role as a firm classroom manager is culturally acceptable, with teachers expected to have power and authority over their students. In contrast, the MOE's framework has the teacher and students interacting more equally with the teacher spending most time and effort facilitating learning rather than regulating student behaviour.

The element of student self-regulation as promoted by the MOE's framework can be difficult to apply when the school stakeholders still perceive student regulation as the teacher's responsibility. This has meant that these practices all revolve around understanding the teaching-learning process as teacher-centred rather than student-centred. Considerable parts of these teachers' classroom practice denied this rhetorical emphasis. These findings contradict some literature (Glasser, 1986; Groundwater-Smith et al., 1998; Killen, 2005; Meichenbaum \& Biemiller, 1998; Zimmerman, 1989) that argues that giving students opportunities to regulate their behaviours provides them with a sense of responsibility for their behaviours, rather than letting all responsibility rest with the teacher. The teacher's role is to have students feel satisfaction for regulating their behaviour when performing their learning tasks.

\subsection{Significance}

The NSWQT Model strongly suggests using narrative as a teaching strategy for dealing with cultural complexities, which is also supported by the literature (Christie, 1985; Egan, 1988, 1997; Hymes, 1996; Luke, 1988), while the Jordanian framework does not. However, teachers implement the element of narrative, to some extent, in their teaching activities. The observed teachers were mostly using an expository approach to teaching. Some narrative was evident in some observed lessons but rarely in mathematics lessons. In Arabic language lessons, it was evident sometimes because of the nature of the topics being taught rather than being intentionally 
used as an element of quality teaching. Teachers may not be aware of the importance of narrative in quality teaching and learning.

In the classroom practices, the element of cultural knowledge in NSWQT Model's and the MOE's framework was incongruent with the observed teaching and learning practices. The Jordanian community is relatively homogeneous in terms of religion, ethnicity, race and language. The classrooms observed for this research did not have different cultural groups that allowed the teachers' knowledge of different cultures to be examined. The MOE is aware of the importance of the element of cultural knowledge, but it remains implicit in official documents. The element of cultural knowledge was not a feature of any of the 14 observed lessons. Political and social demographic changes in the region (Al-Daami \& Wallance, 2007) may make cultural knowledge more of an issue for Jordanian teachers in the future. In multicultural classrooms, teachers need to understand and implement this element as part of the day-to-day quality teaching and learning practices for all students. Previous research (Johnson \& Cupitt, 2004; Keddie, 2005; Loughland, 2006) contradicts the findings of this research in so far as these studies argue that background (cultural) knowledge and narrative are key elements in making the teaching and learning process significant for students. The findings of the present study also seem to contradict earlier literature as to the real centrality of cultural facility for quality teaching.

\section{Future Directions for Policy and Practices}

It can be concluded from this study that there were some congruities between the ideal and the actual quality teaching practices in the inclusive primary classrooms. However, there is gap between the MOE's ideal quality teaching practices and the actual quality teaching practices in the inclusive primary classrooms in some elements of the quality teaching. To narrow that gap, the MOE and the school stakeholders need to develop a joint understanding of the concept of quality teaching that can overcome the confusion and ambiguity of interpretation between the two parties.

For the MOE's ideal quality teaching practices to be implemented, some issues need to be resolved. These issues are the Jordanian teachers' understanding of the teachers' and students' roles in the teaching and learning process. The concept and beliefs come from the teachers' transmission approach to teaching and learning and is connected to other contextual and cultural issues. Both the MOE and the NSWQT Model - as an instrument for this study - introduced quality teaching best practices drawing on the relatively new constructivist approach. This approach calls for teaching to be centred on the student rather than on the teacher. The teacher's role in this process is to be a facilitator and guide for the students, allowing the students to construct their own knowledge and make sense of it, rather than the teacher being a prompter or spoon-feeder. Under this approach students have to be critical thinkers, and problem solvers, and subsequently they should have their own preferences in learning. This does not match with traditional beliefs, not just among teachers but also among students, and their social and cultural context. For the MOE to implement its framework, these issues need to be resolved before any attempts at change. In the study, the elements of student direction, cultural knowledge, problematic knowledge and narrative were either marginally evident or not evident in the observed lessons. These elements could be highlighted and illustrated in the initial teacher training, and to be part of their teaching education programs as essential elements in quality teaching and learning practices.

It would be more effective if primary school teachers were provided with sufficient pre-service and in-service training programs for pedagogic skills in mathematics, by both the universities and the MOE. The study showed that the applicability or congruence of the three dimensions (intellectual quality, quality learning environment and significance) of the NSWQT Model were more clear in Arabic language lessons than mathematics lessons, with higher scores in Arabic language. This suggests that teacher pre-service and in-service preparation programs for mathematics teaching skills are insufficient.

The primary school curriculum could be updated to meet the needs of quality teaching conditions. A national curriculum conference to create a strategic policy on developing a primary education curriculum that meets students' future needs should be considered. Furthermore, the primary school curriculum needs to be updated, reduced and more time allowed to integrate aspects of instructional content knowledge that would enhance students' knowledge and give teachers and students more time to focus on quality work special for students with special needs.

Preliminary teacher education and ongoing professional development for primary school teachers could be enhanced. It is the task of the universities and the MOE to ensure that teacher educators are competent and knowledgeable and that all pre-service teachers have sufficient and comprehensive teaching practices before entering the profession. Furthermore, the MOE could update the training and workshops programs for teachers during their professional service. The professional standards for teacher evaluation and mentoring could be 
extended by providing teachers with the opportunity for self- and peer-evaluation and mentoring. The feedback from this would assist teachers in developing their teaching practices.

Teacher education programmes in Jordan could be updated and sophistically derived from the MOE vision. Care could be taken in designing relevant policies and implementation plans to promote and support quality teaching policies and practices in the inclusive classrooms. Collaboration between school stakeholders will assist and implement more effectively quality teaching elements and develop teachers professionally towards the new quality teaching and learning approaches (student-centred rather than teacher-centred).

\section{References}

Ainscow, M. (1991). Effective School for All. London: David Fulton Publishers.

Al-Daami, K. K., \& Wallance, G. (2007). Curriculum Reform in a Global Context: A Study of Teachers in Jordan. Journal of Curriculum Studies, 39(3), 339-360. http://dx.doi.org/10.1080/00220270601057790

Alnahar, T., \& Kishik, R. (1994). The Life Basic Skills of the Fourth Grade Students in Jordan (in Arabic). Amman: The National Centre for Research and Educational Development.

Alshurfat, S. (2003). The Role of Primary School Teachers in Education Change in Jordan. Unpublished Doctor of Philosophy Thesis, University of Western Sydney, Sydney.

Anani, H., \& Al-Qaisee, H. (1994). The Standard Achievement in Mathematics of the Fourth Grade Students in Jordan (in Arabic). Amman: The National Centre for Research and Educational Development.

Beane, J. A. (1993). A Middle School Curriculum: From Rhetoric to Reality (2nd ed.). Ohio: National Middle School Association.

Biggs, J. B. (Ed.). (1991). Teaching for Learning. Melbourne: Australian Council for Educational Research.

Bruner, J. S. (1960). The Process of Education. Cambridge: Harvard University Press.

Chorrojprasert, L. (2005). The Use of Teaching Portfolios by Secondary School Teachers in Thailand. Unpublished Doctor of Philosophy Thesis, University of Wollongong, Wollongong.

Christie, M. J. (1985). Aboriginal Perspectives on Experience and Learning: The Role of Language in Aboriginal Education. Geelong: Deakin University Press.

Dewey, J. (1916). Democracy and Education: An Introduction to the Philosophy of Education. New York: Macmillan Company.

Egan, K. (1988). Teaching as Story Telling: An Alternative Approach to Teaching and the Curriculum. Chicago: Routledge.

Egan, K. (1997). The Educated Mind. http://dx.doi.org/10.7208/chicago/9780226190402.001.0001

Fullan, M. (1997). Emotion and Hope: Constructive Concepts for Complex Times. In A. Hargreaves (Ed.), Rethinking Educational Change with Heart and Mind. The 1997 ASCD Yearbook (pp. 216-233). Alexandria, VA: ASCD.

Glasser, W. (1986). Control Theory in the Classroom. New York: Harper and Row.

Goodlad, J. I. (1984). A Place Called School: Prospects for the Future. New York: McGraw-Hill.

Gore, J., Griffiths, T., \& Ladwig, J. (2001). Productive Pedagogy as a Framework for Teacher Education: Towards Better Teaching. Paper presented at the AARE Conference, Fremantle.

Groundwater-Smith, S., Cusworth, R., \& Dobbins, R. (1998). Teaching Challenges and Dilemmas. Sydney: Harcourt Brace.

Hargreaves, A. (2003). Teaching in the Knowledge Society: Education in the Age of Insecurity. New York: Teachers College Press.

Hymes, D. (1996). Ethnography, Linguistics, Narrative Inequality: Toward an Understanding of Voice. London: Taylor and Francis.

Jaradat, I., Obedat, S., Abugazalah, H., \& Abdullatef, K. (1983). Effective Instruction (in Arabic). Amman: Educational Library.

Johnson, K., \& Cupitt, G. (2004). Quality Teaching in Mathematics K-6: Perspectives on Classroom-Based Research and Teacher Professional Learning in PSFP Primary Schools. Paper presented at the AARE Conference. 
Keddie, A. (2005). A Framework for 'Best Practice' on Boys' Education: Key Requisite Knowledges and Productive Pedagogies. Pedagogy, Culture and Society, 13(1), 59-74. http://dx.doi.org/10.1080/14681360 500200215

Killen, R. (2005). Programming and Assessment for Quality in Teaching and Learning. Southbank, Vic: Thomson.

King, M. B., Schroeder, J., \& Chawszczewski, D. (2001). Authentic Assessment and Student Performance in Inclusive Schools. Retrieved July 7, 2005, from http://www.wcer.wisc.edu/riser/Brief\%205.pdf

Ladwig, J. G. (2005). Monitoring the Quality of Pedagogy. Leading \& Managing, 11(2), 70-83.

Larrivee, B. (1985). Effective Teaching for Successful Mainstreaming. New York: Longman.

Loughland, A. (2006). The Relationship of Pedagogy and Students' Understanding of Environment in Environmental Education. Unpublished Doctor of Philosophy Thesis, University of Technology, Sydney.

Luke, A. (1988). Literacy, Textbooks and Ideology. London: Falmer Press.

May, T. (2001). Social Research: Issues, Methods and Process (3rd ed.). Buckingham: Open University Press.

McLaughlin, M., \& Talbert, J. (1993). Introduction: New Visions of Teaching. In D. Cohen, M. McLaughlin, \& J. Talbert (Eds.), Teaching for Understanding: Challenges for Policy and Practice (pp. 1-10). San Francisco: Jossey-Bass Publishers.

Meichenbaum, D., \& Biemiller, A. (1998). Nurturing Independent Learners: Helping Students Take Charge of Their Learning. Cambridge: Brookline Books.

Ministry of Education. (2002). Towards a Vision for a New Education System: Vision Forum for the Future of Education in Jordan. Amman, Jordan: Ministry of Education.

Ministry of Education. (2003a). Education Reform for Knowledge Economy. Amman: Ministry of Education.

Ministry of Education. (2003b). General Framework: Curriculum and Assessment (Draft). Unpublished manuscript, Amman.

Ministry of Education. (2004b). The Development of Education: National Report of the Hashemite Kingdom of Jordan. Amman, Jordan: Ministry of Education.

Ministry of Education. (2006a). General Framework: Curriculum and Assessment (in Arabic). Amman, Jordan: Ministry of Education.

Newmann, F., \& Associates. (1996). Authentic Achievement: Restructuring Schools for Intellectual Quality. San Francisco: Jossey-Bass Publishers. http://dx.doi.org/10.1086/444136

Newmann, F., Bryk, A., \& Nagaoka, J. (2001). Authentic Intellectual Work and Standardized Tests: Conflict or Coexistence? Chicago: Consortium on Chicago School Research.

Newmann, F., Marks, H., \& Gamoran, A. (1996). Authentic Pedagogy and Student Performance. American Journal of Education, 104(August), 280-312.

NSW Department of Education. (2003). Quality Teaching in New South Wales Public Schools: An Annotated Bibliography. Sydney: NSW Department of Education and Training.

NSW Department of Education and Training. (2003a). Quality Teaching in New South Wales Public Schools: A Classroom Practice Guide. Sydney: NSW Department of Education and Training.

NSW Department of Education and Training. (2003b). Quality Teaching in New South Wales Public Schools: Continuing the Discussion About Classroom Practice. Sydney: NSW Department of Education and Training.

NSW Department of Education and Training. (2003c). Quality Teaching in New South Wales Public Schools: Discussion Paper. Sydney: NSW Department of Education and Training.

Rosenshine, B., \& Meister, C. (1992). The Use of Scaffolds for Teaching Higher-Level Cognitive Strategies. Educational Leadership, 49(7), 26-33.

Rudy, D., Grusec, J. E., \& Wolfe, J. (1999). Implications of Cross-cultural Findings for a Theory of Family Socialisation. Journal of Moral Education, 28(3), 299-310. http://dx.doi.org/10.1080/030572499103098

Smith, J. B., Lee, V. E., \& Newmann, F. M. (2001). Instruction and Achievement in Chicago Elementary Schools. Chicago: Consortium on Chicago School Research 
University of Queensland. (2001). The Queensland School Reform Longitudinal Study: Supplementary Material. Brisbane: Education Queensland.

Zimmerman, B. J. (1989). Models of Self-Regulated Learning and Academic Achievement. In B. Zimmerman \& D. Schunk (Eds.), Self-Regulated Learning and Academic Achievement: Theory, Research, and Practice (pp. 1-25). New York: Springer-Verlag. http://dx.doi.org/10.1007/978-1-4612-3618-4

\section{Copyrights}

Copyright for this article is retained by the author(s), with first publication rights granted to the journal.

This is an open-access article distributed under the terms and conditions of the Creative Commons Attribution license (http://creativecommons.org/licenses/by/3.0/). 